\title{
Importance of database for direct marketing campaigns
}

\author{
Diana Prihoanca, Ph.D „Vasile Alecsandri” University of Bacau
}

\begin{abstract}
:
Direct marketing activities involve interactivity and customization which requires a good knowledge of current and potential customers. Information that define consumer profile from geographical, demographic, psychographic and behavioral point of view are contained within a database.
\end{abstract}

Keywords: direct marketing, direct marketing campaign, database, customers

\section{JEL Code: M 39}

Direct marketing is "implementation, registration, analysis and planned tracking of clients behaviors regarding the response directly to a time frame to get future marketing strategies, to develop long-term customer loyalty and to ensure continuity of business development."1 The essence of direct marketing can be summarized in the following ${ }^{2}$ :

- directed. Messages are made for each consumer segment in part according to their characteristics to generate a greater rate of response;

- direct. Communication between transmitter and receiver is carried out directly, without intermediaries;

- marketing. By specific direct marketing techniques, helps to meet the needs of current and prospective customers to maximize profit and to achieve other goals.

Direct marketing takes three additional important features:

- relies on direct answers. The client involved in a direct marketing campaign will respond by mail, telephone, Internet, fax, SMS. It has an important role in the monitoring of feedback;

- direct marketing campaigns have a measurable character, since responses are measured, evaluated and analysed;

- requires the construction and maintenance of a database of current and potential clients.

Justification of direct responses is the consequence of direct communication which aims to stimulate a reaction of some kind from the receiver, to generate a specific consumer behavior, differentiated according to the specific objectives pursued, raising it to react in specific campaigns carried out. ${ }^{3}$

Direct marketing campaigns are conditioned by the establishment and observance of five essential steps ${ }^{4}$ :

- $\quad$ establishing the objectives of the campaign;

- $\quad$ knowledge of the target customer segment;

${ }^{1}$ Stone,M., Bond, A., Blake, A. - The complete direct marketing and interactive, BIC ALL Publishing, Bucharest, 2006, p.18.

${ }^{2}$ Stone,M., Bond, A., Blake, A. - The complete direct marketing and interactive, BIC ALL

Publishing, Bucharest, București, 2006, p.18.

${ }^{3}$ Vegheş, C. - Direct marketing, Uranus Publishing, Bucharest, 2003, p.27.

${ }^{4}$ www.marketingdirect.ro 
- design a promotional message and a relevant offer;

- the existence of an interface to receive quick and correct answer;

- analysis of the results of the campaign in close correlation with the objectives set initially. Being a marketing feature, but also the source of defining the segment of customers of direct marketing campaigns within the framework of this work I'll give more attention to the database.

Due to the absence of a database, direct marketing campaigns may not be carried out, direct marketing terms and database were often used as synonyms.

A database used within marketing campaigns directly contribute to building relationships with customers through effective management of historical data and behavioral of their marketing activities (figure 1.)

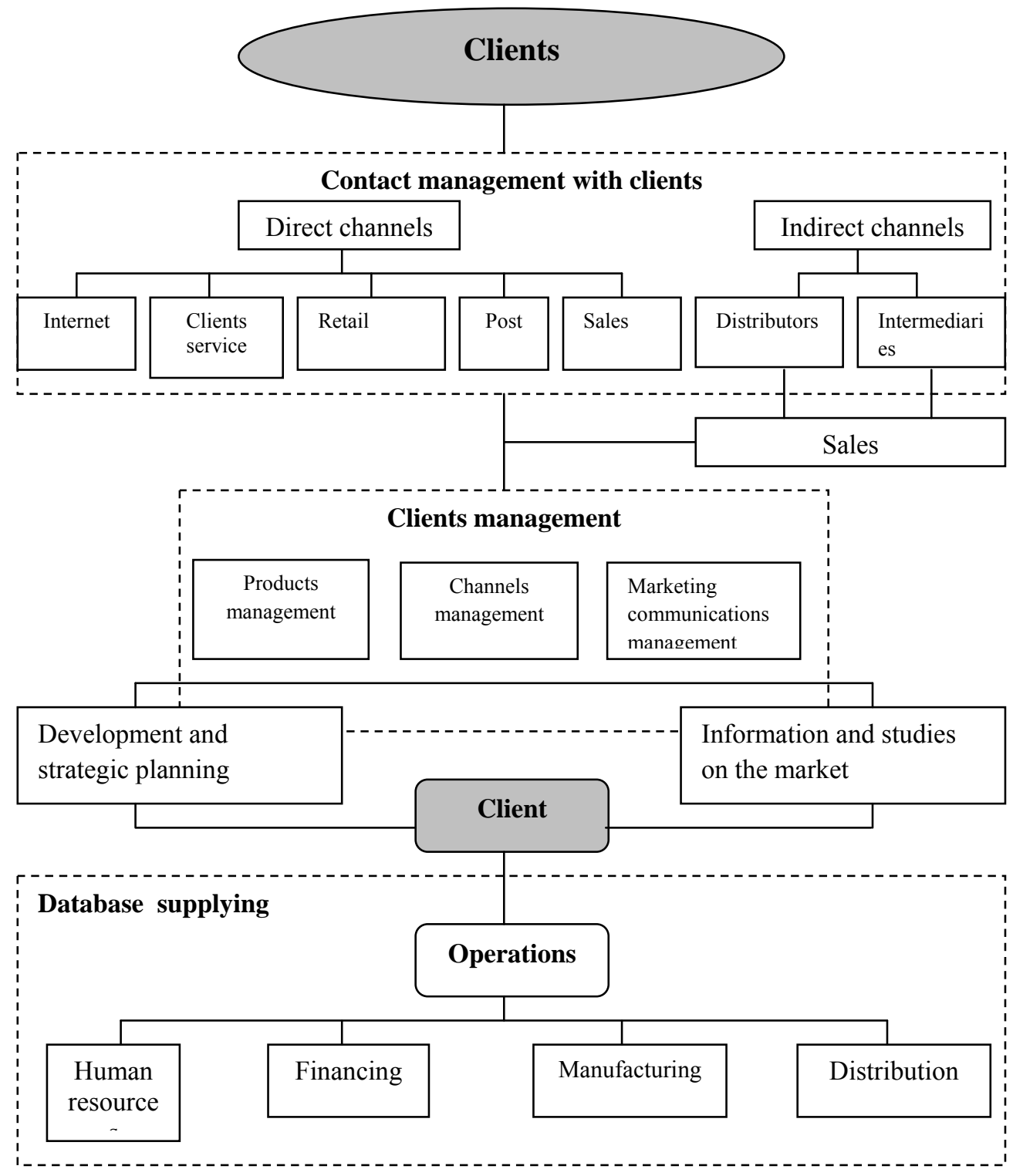

Figure 1 Customer relationships in direct marketing

Sursa: Stone, B., Jacobs, R. - Successful Direct Marketing Methods, ARC Publishing, Chisinau, 2002, p. 57 
Starting from the many definitions given in the literature, a database can be defined as „a computerized data management whose components are represented by data contained and structured, management equipment (hardware database) management applications (software component database), users (intermediaries or end-users) and procedures for specific use". 5

In the classification of databases you can use two criteria: their size and nature. Depending on the size, the database can be associated with terms such as: database, data center or data warehouse, and depending on their nature, databases can be internal or external.

The simplest form of the database is the list of names and addresses of a group of current and/or potential customers who have shared a number of features. In the data list are listed in alphabetical order by last name and are accessed randomly. At the other pole there is a database built on a complex structure that can hold together a virtually unlimited number of variables in a dynamic way. In practice activity of direct marketing campaigns there are used two types of databases: inactive files and relational database..

The inactive file is a list arranged in a sequential order, most often after the serial number of your customers. Customer files must have the same form, and have in their content: a number of the customer, the last name, zip code and phone numbers to which they may be contacted.

Since the signal is acquired sequentially, the use of their inactive files is impractical in the conditions under which it is added customer features regarding the behavior of purchase or consumption, lifestyle, demographic indicators, etc.

\begin{tabular}{|l||l|}
\hline \begin{tabular}{l} 
Supplier \\
Supplier ID- \\
Name of \\
company. \\
Contact person. \\
Title of contact. \\
Address. \\
City. \\
$\begin{array}{l}\text { Region. } \\
\text { Zip/Postal Code. } \\
\text { Country. } \\
\text { Fax } \\
\text { Pagină web }\end{array}$ \\
\cline { 1 - 1 } $\begin{array}{l}\text { Category } \\
\text { ID-ul categoriei } \\
\text { The name of the } \\
\text { class. } \\
\text { Description. } \\
\text { Image }\end{array}$ \\
Product ID \\
product. \\
Provider ID. \\
ID category. \\
The quantity per \\
unit. \\
Unit price. \\
Units in stock. \\
Units ordered. \\
The control of \\
restocking. \\
Surrender.
\end{tabular} \\
\\
\end{tabular}

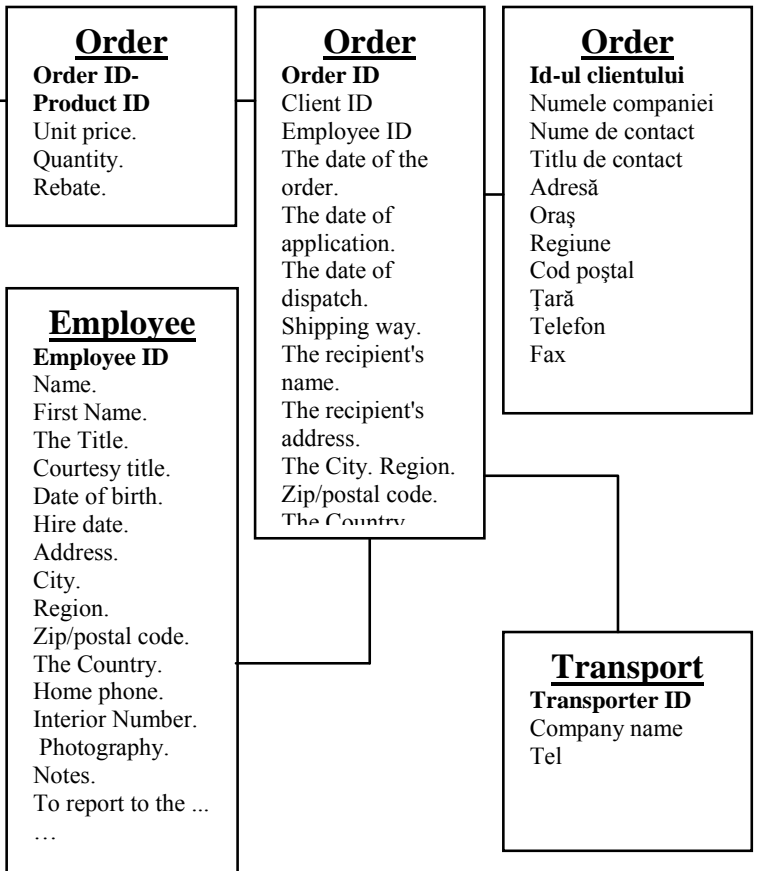

Figure 2. The relational database used in the campaigns of direct marketing B-to-B

Sursa: Stone, B., Jacobs, R. - Successful Direct Marketing Methods, ARC Publishing, Chisinau, 2002, p. 58

${ }^{5}$ Vegheş, C. - Direct marketing, Uranus Publishing, Bucharest, 2003, p.120. 
The database of relational type, in which the data are stored in the tables, it allows the reducing the time of processing, by the existence of a single item from a table linked to a single component from another table (figure 2). The information in the tables is done in rows and columns after different criteria of the data or texts collected.

By the end of the table, it is established the reference points of the way the ranking of the data in the fields contained in the columns or rows. Although in the tables the information is numerous, at the time of processing it is only used only the information that makes "connection".

Use of the databases in campaigns of direct marketing involves achieving specific objectives:

- the correct orientation of the campaign by defining more precisely the target group of clients;

- identification of the firm's strategic customers by building the profile of the "customer" and the identification of all reviews that match this profile;

- optimisation of direct communication through the use of direct marketing techniques and promotional messages in relation to the profile of clients;

- the creation of a long-term relationships with our customers through the information necessary to start and maintain held dialogue with them;

- ensure the necessary support for the activities of marketing, through the data contained can be behavioral profiles as well as modeling and forecasting the behaviour of buying and consumer reviews;

- design and implement direct marketing campaigns by creating a controlled environment characterized by the use of mechanisms, instruments and procedures of coordonation and evaluation of their efficiency

The starting point of the creation of a database is the two sides that characterizes the essential: the marketing (defines the content, structure and use) and the technical side (defines the procedures for the management of the database) and the objectives pursued by building it. The database approach is usually done in conjunction with direct marketing, but in fact it must be regarded as a tool that can be used in different areas of marketing activity in general.

The database must be created to allow carrying out a steady stream of activities associated with its use in the direct marketing campaigns (Figure 3). The data contained in the customer data (individual and organizational) are generally limited to the name or name and full address.

In order to have a clearer picture about the reviews, you can add information about the demographic, geographical, behavioral and psychographic characteristics. In general it can be said that a database built correctly and completely must consist of five categories of data:

- data for the identification of clients;

- data for building profile;

- transactional nature data;

- data on designing direct marketing campaigns;

- other information considered to be important in a given context.

The data contained in the database come from two types of sources: internal and external. Internal data (data of the firm) are customer data from transactions already carried out with them. External data are data obtained from suppliers outside the company with reference to the market and its areas of interest. 


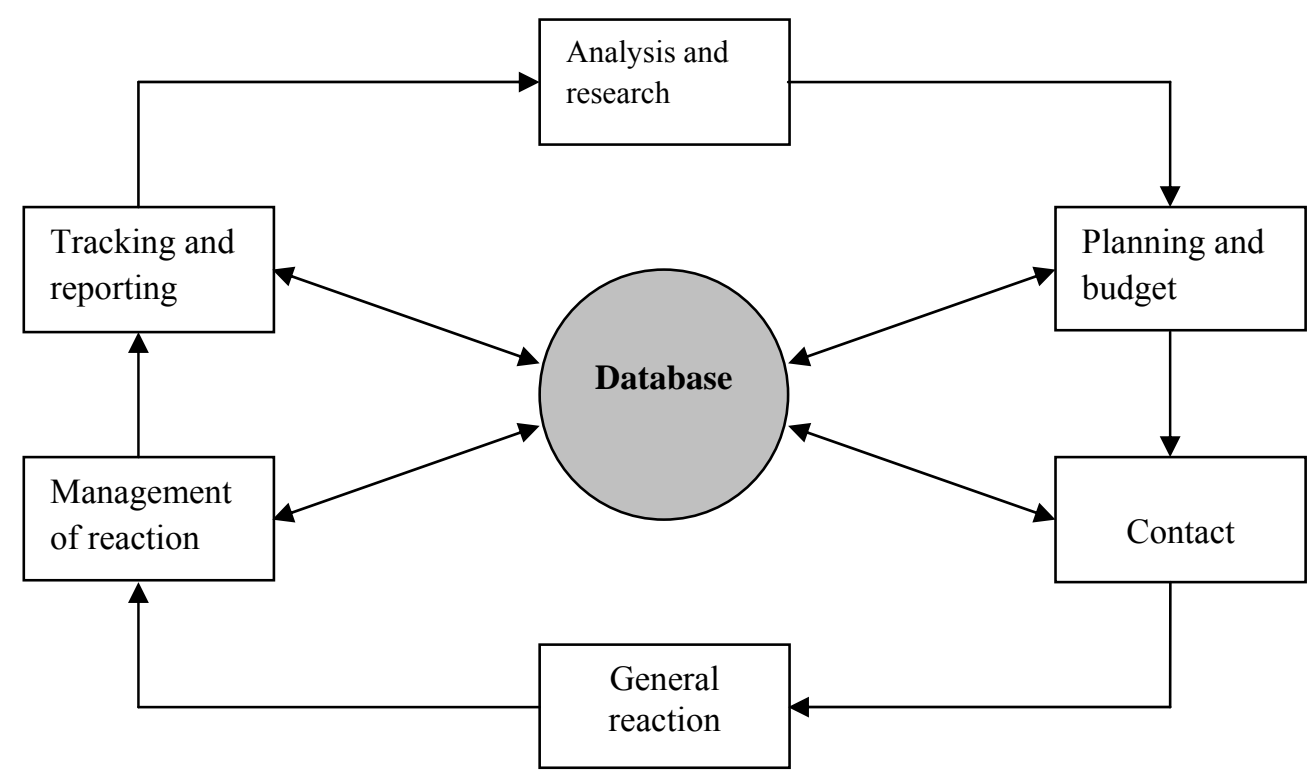

Figura 3 The mechanism for use of the data base in direct marketing

Sursa: Vegheş, C. - Direct marketing, Uranus Publishing, Bucharest, 2003, p.124.

Multiplicity and diversity of external sources of information imposed their classification after several criteria ${ }^{6}$ :

- Depending on the degree of specialization: sources and specialized sources;

- depending on the level of specialisation: general sources and specific sources;

- depending on the costs associated with the provision data: sources free of charge and commercial sources:

- depending on the regime of property: External sources which are difficult to sell and external sources to be hires;

- depending on the format and access to data: printed, on magnetic media, in electronic format, or for online access.

On the other hand, the data contained in the databases is perishable.

Information showing fluctuations are linked to: the level of activity (or inactivity) of customers, demographic characteristics, attitudes, preferences, lifestyle, etc. This instability leads to the need for permanent update of the information on the contents of the databases.

Effective management of data contained in the structure of the databases is done with the help of programs used to create, use and maintenance. In the literature these programs are known under the name of systems in the management of the database (SGBD).

Directions for Use of the database are defined by the customers company, which from the point of view of their status are classified in such commercial:

- potential customers;

- $\quad$ new customers (the period of collaboration less than four months);

- customers in growth (period of collaboration between four and 12 months);

- mature customers (period of collaboration of at least a year).

Importance of the data base in campaigns of direct marketing is given by the advantages that it offers, namely:

\footnotetext{
${ }^{6}$ Vegheş, C. - Direct marketing, Uranus Publishing, Bucharest, 2003, p.127-128.
} 
- measurability. Firms know, through the specific criteria of the database, the characteristics of the target consumers for each campaign carried out;

- testability. To optimize direct marketing campaigns that will be carried out, tests may be carried out on the basis of the assessment of fair and accurate of the campaigns already undertaken.

- $\quad$ selectivity. The criteria that define the structure of the databases allows the selection of the target group of customers that will be the subject of future direct marketing campaigns;

- Customizing. The information provided by the database allow the design of differentiated messages for each segment of customers, and in some cases and for each client;

- flexibility. Based on the existing relationships between the characteristics of customers in the database and the specific direct marketing campaigns is possible to adapt them to the characteristics of the target group of clients.

With a database of well designed and managed, direct marketing can be characterized as a continuous process of growth of the portfolio of customers who meet the needs of existing customers by developing their value for the company and turning them into loyal customers.

\section{Bibliografy:}

1. Claezssen, Y, Deydier, A., Riquet, Y. - Multichannel direct marketing, Polirom Publishing, Bucharest, 2009.

2. Stone,M., Bond, A., Blake, A. - The complete direct marketing and interactive, BIC ALL Publishing, Bucharest, 2006.

3. Stone, B., Jacobs, R. - Successful Direct Marketing Methods, ARC Publishing, Chisinau, 2002.

4. Vegheş, C. - Direct marketing, Uranus Publishing, Bucharest, 2003.

5. www.marketingdirect.ro 